\title{
PENGARUH HEDONIC SHOPPING VALUE DAN ATMOSFER GERAI TERHADAP KEPUTUSAN PEMBELIAN IMPULSIF DENGAN DIMEDIASI REAKSI IMPULSIF
}

\author{
Trecya Gita Maya Kartika, Rofiaty, Fatchur Rohman
}

Pascasarjana Fakultas Ekonomi dan Bisnis Universitas Brawijaya

Email: tg.mayakartika@yahoo.co.id

\begin{abstract}
This study aims to find out and analyze the effect of hedonic shoping value and store atmosphere on impulsive reaction and decision making, the influence of impulsive reactions to impulsive buying decisions, and how the role of impulsive reactions in mediating the influence of hedonic shoping value and the outlet atmosphere against reaction and impulsive purchasing decisions. Target population in this study is consumers Matahari Department Store Malang with the number of samples of 170 respondents. The sample was taken using non probability technique, with purposive sample technique and then the data obtained from the sample were analyzed using Partial Least Square (PLS) with path analysis. The results showed that there is significant influence between hedonic shopping value on impulsive buying decision and impulsive reaction. Atmospheric outlets affect the impulse reaction and impulsive buying decisions. Impulsive reactions have an effect on impulsive purchasing decisions. Impulsive reactions act as partial mediation in the influence of hedonic shopping value on impulse buying decisions and store atmosphere to impulsive buying decisions, which indicate that hedonic shopping value and store atmosphere can influence impulsive buying decisions well with or without the support of impulsive reactions.
\end{abstract}

Keywords: Hedonic shopping value, store atmosphere, impulsive reaction, impulsive purchase decision and Matahari Department Store.

\begin{abstract}
Abstrak: Penelitian ini bertujuan untuk mengetahui dan menganalisis pengaruh dari hedonic shoping value dan atmosfir gerai terhadap reaksi dan keputusan pembelian impulsif, pengaruh reaksi impulsif terhadap keputusan pembelian impulsive, serta bagaimana peran reaksi impulsif dalam memediasi pengaruh dari hedonic shoping value dan atmosfir gerai terhadap reaksi dan keputusan pembelian impulsif. Target populasi pada penelitian ini adalah konsumen Matahari Department Store Kota Malang dengan jumlah sampel sebanyak 170 responden. Sampel diambil dengan menggunakan teknik non probability, dengan teknik purposive sample dan kemudian data yang diperoleh dari sampel dianalisis menggunakan Partial Least Square (PLS) dengan analisis jalur (path analysis). Hasil penelitian menunjukkan bahwa terdapat pengaruh signifikan antara hedonic shopping value terhadap keputusan pembelian impulsif dan reaksi impulsif. Atmosfer gerai berpengaruh terhadap reaksi implsif dan keputusan pembelian impulsif. Reaksi impulsif berpengaruh terhadap Keputusan pembelian impulsif. Reaksi impulsif berperan sebagai partial mediation dalam pengaruh hedonic shopping value terhadap keputusan pembelian impulsif dan atmosfer gerai terhadap keputusan pembelian impulsif, yang mengindikasikan bahwa hedonic shopping value dan atmosfer gerai dapat mempengaruhi keputusan pembelian impulsif dengan baik dengan ataupun tanpa didukung oleh adanya reaksi impulsif.
\end{abstract}

Kata kunci: Hedonic shopping value, atmosfer gerai, reaksi impulsif, keputusan pembelian impulsif dan Matahari Department Store. 
Pusat perbelanjaan ritel modern saat ini telah menawarkan berbagai macam kenyamanan, kemudahan, kecepatan dan layanan kepada para konsumennya sehingga pemasar tidak lagi mampu mempertahankan keunggulan bersaing-nya dengan semata-mata hanya mengandalkan cara konvensional didalam melakukan proses pemasarannya yaitu dengan cara menawarkan beraneka macam produk atau jasa, memberi harga murah, dan jam operasi yang lebih lama. Akan tetapi dengan fenomena yang ada akhir-akhir ini aspek hiburan yang digunakan untuk menstimuli konsumen pun mulai banyak di implementasikan sebagai alat bersaing utama. Seperti kita ketahui produkproduk diskon sering kali kita jumpai di pusatpusat perbelanjaan seperti Mall-Mall dan Department Store yang ada. Dalam rangka untuk berko-munikasi dengan pembeli, pemilik mal akan mendapat manfaat dan fungsi dari pengetahuan tentang anteseden untuk belanja. Ma'ruf (2005) menyatakan bahwa produk produk fashion seperti pakaian merupakan salah satu produk yang sering di beli secara impulsif, pernyataan ini diperkuat oleh penelitian yang dilakukan Rani (2006) yang menyatakan bahwa orang yang melakukan belanja impulsif sering kali membeli barang-barang seperti pakaian, perhiasan, make-up, dan benda-benda lain yang dapat meningkatkan penampilan mereka. Berdasarkan penelitian-penelitian yang ada, maka peneliti menetapkan objek penelitian ini pada perusahaan retail yaitu Matahari Department store.

Persaingan bisnis ritel pada Department Store khususnya di Kota Malang semakin hari semakin meningkat dan bersaing ketat. Gerai pertama Matahari Department Store Malang berada pada lokasi yang sangat strategis, yaitu di kawasan sentra perdagangan pasar besar. Seiring dengan semakin berkembangnya pembangunan pusat-pusat perbelanjaan modern di kota Malang, Matahari Department Store membuka gerai kedua yang letaknya berada di dalam pusat perbelanjaan modern yang jauh lebih besar, yaitu Malang Town Square pada tahun 2003. Meskipun saat ini Matahari department store Malang telah memiliki dua gerai store atau toko, persaingan bisnis ritel modern dalam bentuk department store di kota Malang nampaknya akan terus semakin ketat terutama dengan dibukanya Centerpoint Department Store dikawasan perbelanjaan modern Malang Olimpic Garden (MOG) sehingga bertambah pula deretan wisata belanja yang ada di kota Malang. Berbagai macam bentuk promosi telah dilakukan oleh Matahari department store Malang khususnya cabang Malang Town Square ini untuk menarik perhatian pengunjung dan meningkatkan volume penjualan mereka. Berbagai usaha telah dilakukan manajemen Matahari Department Store untuk menciptakan atmosfer gerai yang nyaman dan berkesan guna merangsang terjadinya pembelian oleh konsumen. Cara-cara tersebut antara lain menyediakan musik, penyejuk udara, penataan/display produk, pencahayaan, tata letak produk sejenis juga diletakkan berdekatan agar memudahkan konsumen dan layout gerai yang memudahkan lalu lintas konsumen. Pemberian label potongan diskon adalah satu bentuk promosi yang dilakukan oleh Matahari department store Malang Town Square. Hampir seluruh produk yang ada di Matahari Department Store Malang Town Square berlabelkan diskon (sale) antara $10 \%$ hingga $70 \%$. Penawaran tersebut tentu saja akan memberikan insentif yang menguntungkan bagi konsumen karena konsumen bisa mendapatkan produk yang diinginkan jauh dibawah harga normal. Selain hal tersebut, atribut-atribut yang ada di toko (store attributes) juga memainkan peran yang tak kalah pentingnya dalam menentukan keberadaan konsumen pada saat berbelanja di dalam store atau toko Matahari Department Store.

Aktivitas berbelanja tanpa disadari menciptakan suatu prilaku konsumen yang unik yaitu perilaku pembelian impulsif. Seperti yang sering dialami sebagian orang,mereka seringkali berbelanja melebihi apa yang direncanakan semula bahkan tidak sedikit mereka membeli barang-barang yang tidak masuk dalam daftar belanja yang sudah dipersiapkan. Sering seseorang melakukan aktivitas berbelanja bukan hanya untuk memenuhi kebutuhan sehariharinya tetapi juga untuk memenuhi keinginan pribadi masing-masing orang. Babin et al., (1994) menyatakan bahwa motivasi berbelanja dapat dikategorikan dalam dua aspek yaitu aspek utilitarian dan hedonic. Silvera et al., (2008) mengemukakan bahwa pembeli impulsif 
lebih memperhatikan pertimbangan hedonis dibandingkan pertimbangan utilitarian pada pembelian yang dilakukan, dan pengalaman berbelanja yang dirasakan cenderung didorong oleh emosi yang tinggi seperti kegembiraan dan kesenangan. Hal ini juga terbukti dalam penelitian yang dilakukan oleh Rachmawati (2009) menunjukan bahwa faktor internal seperti hedonic shopping value dan emosi positif secara positif mempengaruhi keputusan pembelian impulsif. Ditinjau dari prosesnya, pembelian impulsif terjadi lebih singkat dibanding dengan tahap pengambilan keputusan yang biasanya dilakukan karena biasanya pada prilaku pembelian impulsif proses seleksi dan pencarian informasi atas produk seringkali tidak dihiraukan oleh konsumen. Hal ini dikarenakan pada aktivitas pembelian impulsive konsumen merasakan dorongan yang sangat kuat untuk sesegera mungkin membeli barang (Rook dalam Hausman, 2000). Zhang et al., (2011) juga menemukan bahwa nilai hedonis merupakan realisasi dari rangsangan lingkungan berbelanja (atmosfer gerai dan fasilitas pelayanan yang disediakan dalam gerai. Apabila rangsangan disediakan dengan tepat akan dapat menimbulkan ketenangan, relaksasi, pengu-rangan stres, semangat, meningkatkan mood, mempengaruhi keputusan berbelanja, sehingga meningkatkan kemungkinan untuk melakukan pembelian impulsif (Soars, 2009; Thompson, 2011). Peritel seharusnya lebih berfokus pada emosi positif konsumen dan pengalaman hedonic dalam gerai karena dapat meningkatkan terjadinya pembelian impulsif (Park et al., 2006).

Selain dipengaruhi oleh aspek hedonic, prilaku pembelian impulsif konsumen dipengaruhi juga oleh faktor sosial dimana pendapat ini diperkuat oleh Housman (2000) yang menyatakan bahwa prilaku pembelian impulsif berhubungan dengan keinginan untuk memuaskan kebutuhan sosial. Kebutuhan sosial yang dimaksud adalah seperti kebutuhan akan perhatian, afiliasi pada kelompok serta penghargaan dari orang lain (Ma'ruf, 2005). Umumnya manusia tertarik pada penawaran pertama, seperti halnya dengan program potongan harga (price discount) untuk pembelian-pembelian pertama. Program potongan harga bagi konsumen merupakan insentif ekonomi yang efektif sehingga dapat memperolah barang dan jasa lebih banyak dan murah, sehingga faktor ini memegang peranan penting dalam menciptakan keinginan konsumen untuk melakukan pembelian. Penting bagi sebuah Department Store untuk memiliki kemampuan serta berfokus dalam menciptakan emosi positif dan pengalaman hedonik dalam gerai guna mendorong terjadinya pembelian impulsif. Konsumen merasa diingatkan saat memasuki suatu gerai dengan suasana gerai yang familiar sehingga seringkali terjadi pembelian yang tidak direncanakan sebelumnya. Hal ini terbukti pada penelitian yang dilakukan Yistiani dkk.,(2012) yang menyatakan bahwa atmosfer gerai berpengaruh positif dan signifikan terhadap pembelian impulsif. Tidak jarang konsumen berinisiatif mengujungi sebuah gerai berdasarkan pada tawaran harga spesial seperti diskon yang tidak sengaja terlihat saat melintas di depan sebuah gerai atau suasana gerai yang terlihat menarik sehingga menciptakan mood yang akhirnya terjadi pembelian impulsif.Pembelian impulsif semakin intens terjadi saat konsumen berpergian ke suatu pusat perbelanjaan untuk bersenang-senang dengan kolega atau teman di kehidupan seharihari karena disaat emosi seseorang dalam mood yang baik maka kemungkinan reaksi impulsif akan semakin tinggi.

Fenomena-fenomena "impulse buying" seperti ini merupakan sesuatu yang dapat diciptakan. Menciptakan ketertarikan secara emosional seringkali tidak melibatkan rasionalitas dalam proses pengambilan keputusan terutama pada produk Low involvement dan low price, oleh karena itu seringkali perusahaan menyiasati hal ini dengan melakukan program sale/discount pada produkproduk tertentu yang mampu membangun dan menciptakan emosi dan mood konsumen. Lingkungan toko dan faktor social juga berpengaruh positif terhadap respons emosi positif dari konsumen. Perusahaan seharusnya memperhatikan tata letak toko agar produkproduk katagori diskon tersebut mudah terlihat oleh para konsumen sehingga mampu menarik minat konsumen untuk melihat atau bahkan membeli produk tersebut. Reaksi impulsif merupakan kecenderungan dan rangsangan konsumen untuk membeli secara spontan, 
mendadak, segera dan cenderung terjadi secara tiba-tiba (Peck and Childers, 2006). Kecenderungan pembelian impulsif merupakan sifat perseorangan yang muncul sebagai respon atas stimuli lingkungan toko (Park and Lennon, 2006). Reaksi impulsif yang dirasakan oleh seseorang sulit membatasi perilaku dan seringkali konsisten dengan pembelian impulsif di dalam kontek berbelanja.

Semuel (2005) menemukan bahwa lingkungan toko berpengaruh positif terhadap pembelian impulsif. Semakin lama waktu yang diluangkan, konsumen tersebut memiliki kemungkinan yang lebih besar untuk dipengaruhi oleh stimulus-stimulus dalam lingkungan berbelanja yang diciptakan peritel (Beatty dan Ferrell, 1998). Peritel termasuk Matahari Department Store sebaiknya mampu menciptakan dan mengelola atmosfer gerai yang berkesan serta menyediakan pelayanan yang sesuai atau melebihi apa yang diharapkan konsumen. Kondisi tersebut akan dapat membantu untuk membedakan diri dan mampu menciptakan keunggulan kompetitif dari para pesaing. Konsumen akan lebih senang berbelanja jika merasa nyaman ketika berinteraksi dengan lingkungan berbelanja dan kemungkinan besar akan berkunjung kembali ke suatu gerai (Soars,2009). Peritel termasuk Matahari Department Store seharusnya menciptakan dan mengelola atmosfer gerai yang berkesan serta menyediakan pelayanan yang sesuai atau melebihi apa yang diharapkan konsumen. Kondisi tersebut akan dapat membantu untuk membedakan diri dan mampu menciptakan keunggulan kompetitif dari para pesaing. Perbedaan dan perubahan variasi dari atribut toko dapat mempengaruhi tujuan atau motivasi konsumen dalam berbelanja. Arnolds dan Kristy (2003) menjelaskan bahwa terkait dengan hedonic shopping motivations, konsumen memberikan perhatiannya pada atribut toko terkait dengan nilai dari uang. Supermarket dengan kualitas atribut toko yang tinggi menjadi stimulus bagi konsumen sebagai hedonic motivations yang pada gilirannya berdampak pada perilaku loyal. Perbedaanperbedaan hasil penelitian terdahulu memberikan celah dan memberikan ketertarikan lebih bagi peneliti untuk meneliti lebih jauh pengaruh hedonic shopping value, atmosfer gerai terhadap keputusan pembelian impulsif dengan di mediasi reaksi impulsif dalam penelitian ini.

\section{METODE}

Populasi pada penelitian ini adalah konsumen Matahari Department Store Kota Malang dengan jumlah sampel sebanyak 170 responden. Sampel diambil dengan menggunakan teknik non probability, dengan teknik purposive sample dan kemudian data yang diperoleh dari sampel dianalisis menggunakan Partial Least Square (PLS) dengan analisis jalur (path analysis).

\section{HASIL DAN PEMBAHASAN}

Pengujian Hipotesis dan Hasil Analisis Jalur

Dalam PLS pengujian secara statistik setiap hubungan yang dihipotesiskan dilakukan dengan menggunakan simulasi. Dalam hal ini dilakukan metode bootstrap terhadap sampel. Pengujian dengan bootstrap juga dimaksudkan untuk meminimalkan masalah ketidaknormalan data penelitian. Hasil pengujian dengan bootstrapping dari analisis PLS adalah sebagai berikut:

Tabel 1. Path Coefficient (Mean, STDEV, T-Values)

\begin{tabular}{|l|l|l|l|l|l|}
\hline Variabel & $\begin{array}{l}\text { Original } \\
\text { Sample } \\
(\mathbf{O})\end{array}$ & $\begin{array}{l}\text { Sample } \\
\text { Mean } \\
\text { (M) }\end{array}$ & $\begin{array}{l}\text { Standard } \\
\text { Deviation } \\
\text { (STDEV) }\end{array}$ & $\begin{array}{l}\text { Standard } \\
\text { Error } \\
\text { (STERR) }\end{array}$ & $\begin{array}{l}\text { T } \\
\text { Statistics } \\
(\mid \text { O/STER } \\
\text { R|) }\end{array}$ \\
\hline $\begin{array}{l}\text { Hedonic shopping value }-> \\
\text { Reaksi impulsif }\end{array}$ & 0.216 & 0.226 & 0.083 & 0.083 & 2.592 \\
\hline $\begin{array}{l}\text { Hedonic shoping value -> } \\
\text { Keputusan pembelian impulsif }\end{array}$ & 0.379 & 0.388 & 0.067 & 0.067 & 5.635 \\
\hline $\begin{array}{l}\text { Atmosfer Gerai -> } \\
\text { Reaksi impulsif }\end{array}$ & 0.525 & 0.521 & 0.081 & 0.081 & 6.457 \\
\hline
\end{tabular}




\begin{tabular}{|l|l|l|l|l|l|}
\hline Variabel & $\begin{array}{l}\text { Original } \\
\text { Sample } \\
(\mathbf{O})\end{array}$ & $\begin{array}{l}\text { Sample } \\
\text { Mean } \\
\text { (M) }\end{array}$ & $\begin{array}{l}\text { Standard } \\
\text { Deviation } \\
\text { (STDEV) }\end{array}$ & $\begin{array}{l}\text { Standard } \\
\text { Error } \\
\text { (STERR) }\end{array}$ & $\begin{array}{l}\text { T } \\
\text { Statistics } \\
(\mid \mathbf{O} / \text { STER } \\
\text { R|) }\end{array}$ \\
\hline $\begin{array}{l}\text { Atmosfer Gerai }-> \\
\text { Keputusan pembelian impulsif }\end{array}$ & 0.183 & 0.183 & 0.069 & 0.069 & 2.657 \\
\hline $\begin{array}{l}\text { Reaksi impulsif }-> \\
\text { Keputusan pembelian impulsif }\end{array}$ & 0.365 & 0.353 & 0.060 & 0.060 & 6.044 \\
\hline
\end{tabular}

Sumber: data primer diolah, 2016

Pengujian hipotesis pertama menunjukkan bahwa hubungan variabel Hedonic shopping value dengan keputusan pembelian impulsif (Z) menunjukkan nilai $t$ sebesar 5,635. Nilai tersebut lebih besar dari t tabel $(1,960)$. Hasil ini berarti bahwa Hedonic shopping value memiliki pengaruh yang positif dan signifikan secara langsung terhadap Keputusan Pembelian Impulsif yang berarti sesuai dengan hipotesis pertama dimana Hedonic shopping value berpengaruh signifikan terhadap Keputusan Pembelian Impulsif. Hasil penelitian menunjukan bahwa hedonic shopping value berpengaruh secara signifikan terhadap keputusan pembelian impulsif. Makna temuan ini adalah semakin tinggi hedonic shopping value akan mendorong peningkatan keputusan pembelian impulsif konsumen. Analisis deskriptif responden menunjukan bahwa indikator hedonic shopping value menyebabkan konsumen melakukan keputusan pembelian impulsif, hal ini dijelaskan dari semua indikator hedonic shoping value yang mengarah ke keputusan pembelian impulsif ratarata mendapatkan penilaian yang sangat baik dari konsumen. Nilai rata-rata salah satu indikator hedonic shopping value memberikan gambaran bahwa berbelanja di Matahari Department Store mampu menciptakan perasaan senang sehingga konsumen mampu melupakan persoalan yang dihadapi di kehidupan mereka. Secara empiris, penelitian ini mendukung penelitian Veronica Rachmawati (2009) yang menyatakan bahwa Hedonic shopping value memiliki pengaruh yang signifikan terhadap keputusan pembelian impulsif dan penelitian yang dilakukan Kacen and Lee (2002) dan Barley and Nancarrow (1998) dalam Park et al., (2006) yang menyatakan bahwa kesenangan yang dirasakan oleh konsumen pada waktu berbelanja merupakan nilai hedonik yang dapat menimbulkan perilaku pembelian impulsif

Hipotesis kedua menunjukkan bahwa hubungan variabel Hedonic shopping value (X1) dengan reaksi Impulsif $(\mathrm{Y})$ menunjukkan nilai $\mathrm{t}$ sebesar 2,592. Nilai tersebut lebih besar dari $\mathrm{t}$ tabel $(1,960)$. Hasil ini berarti bahwa Hedonic shopping value memiliki pengaruh yang positif dan signifikan terhadap Reaksi Impulsif yang berarti sesuai dengan hipotesis pertama dimana Hedonic shopping value berpengaruh signifikan terhadap Reaksi Impulsif. Nilai hedonis berasal dari perasaan emosional, sukacita dan pelarian diri dari pekerjaan, permasalahan yang dihadapi sehari-hari untukmengungkapkan kepuasan diridan pergaulan seseorang. Analisis Deskripsi responden tentang indikator reaksi impulsif memperoleh nilai rata-rata yang baik, hal ini menjelaskan bahwa dengan ada nya perasaan senang yang berasal dari hedonic shopping value mampu menimbulkan emosi positif yang menghasilkan reaksi spontan/ tiba-tiba bagi konsumen untuk melakukan suatu kegiatan salah satunya melakukan kegiatan pembelian. Reaksi spontan dan tiba-tiba dalam mengambil keputusan pembeliaan tersebut dinamakan reaksi impulsif konsumen. Indikator hedonic shopping value yang dinilai paling mampu meningkat reaksi impulsif konsumen adalah indikator kesenangan baru dimana konsumen menganggap bahwa rasa senang yg diperoleh menjadikan sebagian konsumen mampu melupakan persoalan yang dihadapi dan rasa senang tersebut terkadang menimbulkan suatu reaksi spontan konsumen saat berada di matahari department store. Secara empiris penelitan ini selaras dengan penelitian yang dilakukan oleh Utami (2010) menunjukan bahwa reaksi impulsif di pengaruhi oleh faktorfaktor nilai hedonis yang biasanya menghasilkan kegiatan keputusan pembelian impulsif (impuls buying). 
Hasil pengujian hipotesis ketiga menunjukkan bahwa hubungan variabel Atmosfer Gerai (X2) dengan Reaksi Impulsif (Y) menunjukkan nilai t sebesar 6,457 . Nilai tersebut lebih besar dari t tabel $(1,960)$. Hasil ini berarti bahwa Atmosfer Gerai memiliki pengaruh positif dan signifikan terhadap Reaksi Impulsif. konsumen beranggapan bahwa indikator-indikator yang ada dalam lingkup atmosfer gerai seperti pencahayaan, pengaturan suhu, musik, aroma, warna, pengelompokan produk dan display produkdi Matahari Department Store mampu memberikan suasana nyaman yang bisa mempengaruhi suasana hati konsumen atau mood yang dirasakan konsumen. Alunan musik dan pengaturan suhu dalam gerai dianggap paling mampu menjadikan konsumen betah berlama-lama dalam gerai. Ketika konsumen memiliki perasaan nyaman dan senang maka akan terjadi proses penilaian terhadap lingkungan fisik suatu gerai yang dapat menimbukan reaksi impulsif (Dholkia, 2000;Park dan Lennon, 2000). Hasil penelitian ini didukung oleh penelitian Ma'ruf (2006) yang menyatakan bahwa atmosfer dan ambisi konsumen dapat tercipta dari gabungan unsurunsur Penyajian merchandise dan visual merchandising bertujuan memikat konsumen dari segi penampilan, suara, dan aroma, bahkan pada rupa barang yang disentuh konsumen. Gabungan dari beberapa unsur-unsur atmosfer gerai tersebut dapat mendeskripsikan moment of truth, yaitu situasi langsung yang dirasakan konsumen saat berbelanja. Jika pengaaturan dari gabungan unsur-unsur tersebut dapat berjalan optimal, peritel akan dapat menyentuh emosi konsumen dan memberi pengalaman berbelanja yang akan berdampak pada peluang untuk meningkatkan pangsa pasar serta memenangkan hati konsumen. Ballantine et al. (2010) yang menemukan bahwa elemen-elemen atmosfer gerai dapat menjadikanpengalaman berbelanja konsumen menjadi menyenangkan sehingga membangkitkan emosi konsumen.

Hipotesis keempat menunjukkan bahwa hubungan variabel Reaksi Impulsif $(\mathrm{Y})$ dengan Keputusan Pembelian Impulsif ( $\mathrm{Z}$ ) menunjukkan nilai t sebesar 6,044. Nilai tersebut lebih besar dari t-tabel $(1,960)$. Hal ini membuktikan bahwa semakin tinggi reaksi impulsif yang ada maka semakin memungkinkan untuk terjadinya keputusan pembelian impulsif. Hasil penelitian ini mendukung hasil penelitian Rook and Fisher (1995), yang menyatakan konsumen yang memiliki reaksi impulsif yang tinggi biasanya akan membeli produk secara impulsif. Keputusan pembelian impulsif biasanya terjadi ketika konsumen dihadapkan pada kondisi yang serba terburu-buru sehingga sebagian konsumen tidak berfikir panjang apakah barang yang akan dibeli merupakan produk yang dibutuhkan, konsumen hanya mengandalkan perasaan emosional ketika misalnya konsumen melihat produk-produk yang dianggap menarik sedang mengalami potongan harga sehingga konsumen merasa sayang untuk melewatkan moment yang mereka anggap mungkin tidak akan terulang kembali. Emosi konsumen bisa menjadi sebuahpenentu penting dalam memprediksikan pembelianimpulsif dalam sebuah toko ritel. Konsumen yang emosional akan memiliki keinginan kuat untuk membeli meskipun pada awalnya tidak ada keinginan untuk melakukan pembelian terutama pada produk-produk yang mereka anggap menarik, unik dan lucu. Keputusan pembelian impulsif merupakan masalah internal individu, konsumen mengambil keputusan secara spontan karena pengaruh kondisi emosional individu yang muncul karena melihat produk yang ditawarkan lengkap dan diatur secara menarik.

Hipotesis kelima menunjukkan bahwa hubu-ngan variabel Atmosfer Gerai (X2) dengan Keputusan Pembelian Impulsif (Z) menunjukkan nilai $t$ sebesar 2,657. Nilai tersebut lebih besar dari t tabel $(1,960)$. Hasil ini berarti bahwa atmosfer gerai memiliki pengaruh yang positif dan signifikan terhadap keputusan pembelian impulsif. Konsumen yang merasa nyaman di dalam suatu gerai akan bersedia untuk berlama-lama dalam gerai dan semakin lama waktu yang digunakan konsumen maka akan dimanfaatkan konsumen untuk memilih produk yang diinginkan sehingga semakin kuat muncul dorongan untuk membeli suatu produk, hal ini sesuai dengan hasil penelitianyang dilakukan Park et al.,(1989) yang menunjukkan bahwa semakin lama waktu yang digunakan konsumen berbelanja maka semakin kuat dorongan untuk melakukan pembelian konsumen secara impulsif. Penelitian Youn dan Faber (2000) yang menemukan bahwa atmosfer 
gerai memperbesar kemungkinan terjadinya perilaku impulsif serta penelitian oleh Soars (2009) yang menemukan adanya pengaruh positif atmosfer gerai terhadap pembelian impulsif.Hasil penelitian ini membuktikan bahwa semakin baik atmosfer yang diciptakan oleh matahari departmen store maka semakin tinggi kemungkinan terjadinya keputusan pembelian impulsif konsumen.

Tabel 2. Pengaruh tidak Langsung

\begin{tabular}{|l|l|l|l|l|l|l|l|}
\hline & \multicolumn{2}{|l|}{$\begin{array}{l}\text { Koefisien } \\
\text { Langsung }\end{array}$} & \multicolumn{2}{l|l}{$\begin{array}{l}\text { standar } \\
\text { error }\end{array}$} & Koefisien TL & se Gab & t Hitung \\
\hline $\begin{array}{l}\text { Vedonic shopping value } \\
\text { reaksi impulsif } \\
\text { keputusan pembelian impulsive }\end{array}$ & 0.216 & 0.365 & 0.083 & 0.060 & 0.0786 & 0.0284 & 2.7711 \\
\hline $\begin{array}{l}\text { Atmosfer gerai } \longrightarrow \\
\text { reaksi impulsif } \\
\text { keputusan pembelian impulsive }\end{array}$ & 0.525 & 0.365 & 0.081 & 0.060 & 0.1916 & 0.0481 & 3.9836 \\
\hline
\end{tabular}

Sumber: data primer diolah, 2016

Tabel di atas menunjukkan bahwa hubungan variabel Hedonic shopping value dengan Keputusan Pembelian Impulsif melalui Reaksi Impulsif menunjukkan nilai koefisien jalur tidak langsung sebesar 0,078 dengan nilai $t$ sebesar 2,771. Nilai tersebut lebih besar dari t tabel (1,960). hal ini berarti bahwa Reaksi Impulsif memiliki pengaruh yang signifikan dalam menjembatani Hedonic shopping value terhadap Keputusan Pembelian Impulsif ini berarti hipotesis 6 diterima. Pelaku ritel harus memberikan perhatian pada kondisi emosional positif konsumen dan pengalaman hedonis dalam toko (in-store) mereka karena hal ini dapat memicu perilaku pembelian impulsif, juga pelaku ritel terus menerus mendorong pembelian impulsif yang dilakukan oleh konsumen dan juga mendorong terjadinya reaksi impulsif. Hedonic shopping value merupakan suatu kegiatan berbelanja yang terkadang berlebihan untuk mendapatkan suatu kesenangan sehingga dapat menimbulkan suatu reaksi dari emosi positif konsumen yang akhirnya menyebabkan terjadinya keputusan pembelian impulsif.Ballantine et al. (2010) yang menemukan bahwa elemen-elemen atmosfer gerai dapat menjadikan pengalaman berbelanja konsumen menjadi menyenangkan sehingga membangkitkan reaksi impulsif konsumen dan menghasilkan impulse buying.

Pengujian hipotesis ketujuh menunjukkan bahwa hubungan variabel Atmosfer Gerai dengan Keputusan Pembelian Impulsif ( $Z$ ) melalui Reaksi Impulsif menunjukkan nilai koefisien jalur tidak langsung sebesar 0,1916 dengan nilai t sebesar 2,983. Nilai tersebut lebih besar dari t-tabel $(1,960)$. Hasil ini berarti bahwa Reaksi Impulsif memiliki pengaruh yang signifikan dalam menjembatani Atmosfer Gerai terhadap Keputusan Pembelian Impulsif. Hal ini berarti hipotesis 7 diterima.

\section{KESIMPULAN}

Berdasarkan penelitian yang telah dilakukan dapat diambil kesimpulan sebagai berikut:

1. Hasil penelitian menunjukan bahwa variabel Hedonic shopping value berpengaruh secara langsung dan signifikan terhadap Reaksii Impulsif. Hasil penelitian tersebut menunjukkan hubungan yang positif, artinya jika tingkat Hedonic shopping value semakin meningkat maka Reaksi Impulsif konsumen juga akan mengalami peningkatan.

2. Hasil penelitian menunjukan bahwa variabel hedonic shopping value berpengaruh secara langsung dan signifikan terhadap Keputusan Pembelian Impulsif. Hasil penelitian tersebut menunjukkan hubungan yang positif, artinya semakin kuat hedonic shopping value konsumen akan semakin kuat mendorong peningkatan Keputusan Pembelian Impulsif.

3. Hasil penelitian menunjukan bahwa variabel atmosfer gerai berpengaruh secara langsung dan signifikan terhadap Reaksi Impulsif. Hasil penelitian tersebut menunjukkan hubungan yang positif, artunya jika tingkat atmosfer gerai semakin meningkat maka reaksi impulsif konsumen juga akan meningkat.

4. Hasil penelitian menunjukan bahwa variabel atmosfer gerai berpengaruh secara langsung 
dan signifikan terhadap keputusan pembelian impulsif. Hasil penelitian tersebut menunjukkan hubungan yang positif, artinya jika semakin baik tingkat atmosfer gerai maka akan dapat mendorong peningkatan keputusan pembelian impulsif.

5. Hasil penelitian menunjukan bahwa reaksi impulsif berpengaruh langsung dan signifikan terhadap keputusan pembelian impulsif. Semakin tinggi reaksi impulsif yang ada semakin besar kemungkinan terjadinya keputusan pembelian impulsif.

6. Hasil penelitian menunjukan bahwa variabel Atmosfer Gerai berpengaruh secara tidak langsung dan signifikan terhadap Keputusan Pembelian Impulsif. Hasil penelitian tersebut menunjukkan hubungan yang positif, artinya reaksi impulsif konsumen dapat mendorong terjadinya hubungan antara variabel Atmosfer Gerai dengan Keputusan Pembelian Impulsif.

7. Hasil penelitian menunjukan bahwa variabel Hedonic shopping value berpengaruh secara tidak langsung dan signifikan terhadap Keputusan Pembelian Impulsif. Hasil penelitian tersebut menunjukkan hubungan yang positif. Hasil penelitian tersebut menunjukan bahwa adanya reaksi impulsif akan memperkuat peningkatan variabel Hedonic shopping value dengan Keputusan Pembelian Impulsif.

\section{SARAN}

Berdasarkan kesimpulan di atas, dapat dikemukakan beberapa saran yang diharapkan dapat bermanfaat bagi perusahaan maupun bagi pihak-pihak lain. Adapun saran yang diberikan, antara lain:

1. Diharapkan dengan adanya pengaruh Hedonic shopping value dan atmesfer gerai terhadap keputusan pembelian impulsif pihak perusahaan dapat mempertahankan serta meningkatkan pelayanan terhadap atmosfer gerai, karena apabila Atmosfer Gerai mampu memberikan pelayanan dan kenyamanan yang baik akan menimbulkan reaksi impulsif yang mempunyai pengaruh yang signifikan terhadap Keputusan Pembelian Impulsif melalui reaksi Impulsif, sehingga Keputusan Pembelian Impulsif akan semakin meningkat seiring dengan peningkatan kinerja perusahaan yang berkaitan dengan atmosfer gerai.
2. Pihak Matahari Departement Store Kota Malang perlu menentukan segmentasi pasar yang jelas untuk konsumen yang dilayani. Hal tersebut dianggap perlu karena konsumen Matahari Departement Store Kota Malang kebanyakan yang berusia muda dan kebanyakan berbelanja bersama teman dan keluarga. Segmen pasar Departement Store Kota Malang dapat didasarkan pada demografi konsumen sehingga kejelasan segmen akan membantu pihak Departement Store Kota Malangdalam menentukan target pasar yang ditentukan.

3. Mengingat variabel bebas dalam penelitian ini merupakan hal yang sangat penting dalam mempengaruhi loyalitas konsumen diharapkan hasil penelitian ini dapat dipakai sebagai acuan bagi peneliti selanjutnya untuk mengembangkan penelitian ini dengan mempertimbangkan variabel-variabel lain yang merupakan variabel lain diluar variabel yang sudah masuk dalam penelitian ini.

\section{DAFTAR PUSTAKA}

Arnold, M. J., \& Reynolds, K.,2003. Hedonic shopping motivations. Journal of Retailing, 79(2), 77-95,

Babin, B.J., Darden, W.R., and Grifin, M., 1994.'Work and/or Fun: Measuring Hedonic and Utilitarian Shopping Value". Journal of Consumer Research, 20 (March): 644-656Arnold \& Kristy (2003).

Ballantine, P. W., Jack, R., and Parsons, A. G. 2010. Atmospheric cues and their effect on the hedonic retail experience, International Journal of Retail and Distribution Management Vol. 38 No. 8,pp. 641653.Grayson dan McNeill, 2009

Beatty, S. E., and Ferrell, M. E. 1998. Impulse buying: modeling its precusors, Journal of Retailing, Vol. 74 No. 2. Pp. 169191Weekes, 2004).

Dholakia, U.M.. (2000). Temptation and Resistance: An Integrated Model of Consumption Impulse Formation and Enactment. Journal of Psychology and Marketing. Vol. 17 (11): pp. 955-982.

Fam, K. S., Merrilees, B., Richard, J. E., Jozca, L., Li, Y., and Krisjanous, J. (2011). Instore marketing: a strategic perspective, Asia Pasific Journal of Marketing and Logistics, Vol. 23 No.2, pp. 165-176

Fischer, E., Arnold, S., 1994. Sex, gender identity, gender role attitudes, and 
consumer behavior. Psychology and Marketing 11, 163-182.

Ghozali, I., 2006. Aplikasi Multivariate dengan Program SPSS. Penerbit Universitas Dipenogoro. Semarang

Grayson, R. A. S. and McNeill, L. S. 2009. Using atmospheric elements in service retailing: understanding the bar environment, Journal of Services Marketing, Vol. 23, No. 7, pp. 517-527.

Grace, Debra. O'cass, Aron. 2008. Examining Service Experience and PostConsumption Evaluations.Journal of Service Marketing, Vol. 18

Gultekin, Beyza dan Leyla Ozer. 2012. The Influence of Hedonic Motives and Browsing On Impulse Buying. Journal of Economics and Behavioral Studies. Vol. 4 (3): pp. 180-189.

Hausman, A., 2000, A multi- method investigation of consumer motivations in impulse buying behavior, Journal of Consumer Marketing,

Hausman, A. 2010. A multi-method investigation of consumer motivations in impulse buying behavior.Journal of Consumer Marketing, Vol. 17 No.5, pp. 403-419.

Jonathan Sarwono, Metode Penelitian Kuantitatif \& Kualitatif,Yogyakarta; Graha Ilmu, 2006, Hal. 111

Kuncoro, Mudrajad, 2009, Metode Riset untuk Bisnis dan Ekonomi : Bagaimana Meneliti dan Menulis Tesis?, Edisi 3, Erlangga, Jakarta.

Kacen, J. J., and Lee, J. A. 2002. The influence of culture on consumer impulsive buying behavior, Journal of Consumer Psychology, Vol. 12, No. 2, pp. 163-176

Ma'ruf, H., 2006. Pemasaran Ritel. Jakarta: PT.Gramedia Pustaka Utama.

Park, J. and Lennon, S. J. 2006. Psychological and environmental antecedents of impulse buying tendency the multichannel shopping context, Journal of Consumer Marketing, Vol. 23, No. 2, pp. 58-68

Park, E.J., Kim, E.Y., Forney, JC. 2005 . A structural model of fashion-oriented impulse buying behavior. Journal of Fashion Marketing and Management, Vol. 10 No. 4, pp. 433-446
Rachmawati, Veronika. 2009. Hubungan Antara Hedonic shopping value, Positive Emotion, dan Perilaku Impulse Buying pada Konsumen Ritel. Majalah Ekonomi. Tahun XIX (2): hlm. 192-209.

Rani Agias Fitri. 2006. Terlena dalam nikmatnya Belanja. Suara Pembaruan. Edisi 13 Desember 2006

Rook, D.W. and Fisher, R.J. 1995, Trait and normative aspects of impulsive buying behavior, Journal of Consumer Research, Vol. 22, No. 3, pp. 305-13.

Rohman, Fatchur. 2009. Peran Nilai Hedonik Konsumsi dan Reaksi Impulsif sebagai Mediasi Pengaruh Faktor Situasional terhadap Keputusan Pembelian Impulsif di Butik Kota Malang. Jurnal Aplikasi Manajemen. Vol. 7 (2): hlm. 251-261.

Silvera, D. H., Lavack, A. M., and Kropp, F. 2008. Impulse buying: the role of affect, social influence, and subjective wellbeing, Journal of Consumer Marketing, Vol. 25, No. 1, pp. 23-33.

Semuel, H. 2005. Respon lingkungan berbelanja sebagai stimulus pembelian tidak terencana pada toko serba ada (toserba): studi kasus carrefour surabaya, Jurnal Manajemen dan Kewirausahaan, Vol. 7 No. 2, hal. 152-170 (Kang dan Poaps, 2010).

Soars, B. 2009. Driving sales through shopper's sense of sound, sight, smell, and touch, InternationalJournal of Retail and Distribution Management, Vol. 37 No.3, pp. 286-298

Youn, S. and Faber, R.J. (2000). Impulse buying: its relation to personality traits and cues. Advances in Consumer Research. Vol. 27, pp. 179-85.

Yistiani, Ni Nyoman Manik, Ni Nyoman Kerti Yasa, dan I.G.A Ketut Gede Suasana. 2012. Pengaruh Atmosfer Gerai dan Pelayanan Ritel Terhadap Nilai Hedonik dan Pembelian Impulsif KonsumenMatahari department store Duta Plaza di Denpasar. Jurnal Manajemen, Strategi Bisnis, dan Kewirausahaan Vol. 6 (2): hlm.139-148.

Zhang, Y., Sirion, C., and Combs, H., 2011. The influence of the mall environment on shopper's values and consumer behavior in China, ASBBS Annual Conference, Vol. 18 No. 1, pp. 214-224. 
